\title{
Aiming at the improvement of safety at Indian construction workplace
}

\author{
Vigneshkumar Chellappa ${ }^{1}$, Urmi Ravindra Salve ${ }^{2}$, Roode Liias ${ }^{3}$ \\ ${ }^{1,2}$ Department of Design, Indian Institute of Technology Guwahati, Guwahati, India \\ ${ }^{3}$ Department of Civil Engineering and Architecture, Tallinn University of Technology, Tallinn, Estonia
}

E-mail: ${ }^{1}$ vigneshkumarchellappa@gmail.com (corresponding author)

\begin{abstract}
Accidents in construction industry have the major negative impacts in many countries. The objectives of this paper are: (1) examine the current safety practices in Indian construction industry (2) identify the causes of accidents (3) recommend solutions to improve safety performance at Indian construction workplace. Interviews were conducted with experienced professionals in Indian construction industry. Results indicated that accidents were caused by the combination of organizational and individual factors. Based on these findings, it was suggested that adoption of information technologies in various ways would help to reduce accidents by addressing the following issues (1) safety planning, (2) safety education and (3) safety monitoring.
\end{abstract}

Keywords: accidents, safety, Indian construction, design, information technologies.

\section{Introduction}

Construction industry in both developed and developing countries has documented a poor safety performance (Fewings, 2013). Construction activities result in death to workers (HSE, 2006) especially in large-scale construction projects (Guo, H. Li, \& V. Li, 2013). The administrative, industrial and academic sectors have considered fall as a top priority which accounts for great proportion of accidents at construction sites. In Great Britain, fall accident accounted for 49\% of fatalities during 2013-2017 (HSE, 2018). Similarly, fall deaths in construction industry were responsible for 46\% in Japan during 2015-2017 (JIOSH, 2017). In the period of 2010-2015, fall deaths in USA bears up to 35\% (BLS, 2017). In Hong Kong, fall deaths were accounted for 58\% during the year 2009-2016 (OSHB, 2017) (Huang \& Hinze, 2003) examined 7543 construction accidents which were OSHA investigated between 1990-2001 and concluded that falls are the major cause for accidents.

In India, construction sector is the second largest next to agriculture but accident statistics are not properly and regularly reported (Hämäläinen, 2010). So this is one of the causes for not carrying out enough study on construction safety in India (Zhou, Goh, \& Li, 2015). However, due to dynamic nature and huge number of stakeholder's involvement, it is predictable that Indian construction will account for large number of fatal and non-fatal accidents (Patel \& Jha, 2016). According to 11th Five-Year Plan (2007-12), the Indian construction industry, employing the largest labor force, has accounted for about $11 \%$ of all occupational injuries and $20 \%$ of deaths resulting from occupational incidents (Patel \& Jha, 2016). Attributes in Indian construction industry may differ from project to project (Vigneshkumar, Salve, \& Saravana, 2018). Like other countries, government of India launched different initiatives to improve the poor safety performance at construction workplace in India (Pingle, 2012). Although, accidents on construction workplace still occurs that results in unnecessary fatalities to many workers (Bashir, Suresh, Proverbs, \& Gameson, 2011). It is, however, not clear that why accidents still happen in Indian construction workplaces. Therefore there is a need of deeper understanding of why accidents still happen, what safety practices are being followed and what solutions can be recommended to improve safety performance in construction industry. Thus, the objectives of this paper are: (1) examine the current safety practices in Indian construction industry (2) identify the causes of accidents (3) recommend solutions to improve safety performance at Indian construction workplace.

\section{Methods and materials}

An interview was carried out to reach the three aims. Unsafe conditions are considered as a complex issue in this research. In this study four different large scale construction companies were chosen from southern part of India to know about the current safety practices followed in each. The selection of companies for this research is made from memebers of Confederation of Real Estate Developers Association of India (CREDAI), who are involved in residen- 
tial construction projects and members of the Construction Industry Development Council of India (CIDC). The members of these companies are involved in government organizations and contractual bodies involved in all type of construction projects all over the country and are actively engaged in safety programs. Hence the data are collected from the active members of two groups. Research team targeted to interview with experienced practitioners and experts from above organizations in order to make a comprehensive view of the safety issues from different viewpoints. Among them, the focus is on owners and main contractors who possess the minimum of at least 5 years of experience on execution of projects; this is to confirm the dependability of the received responses. Hence, nine participants from four companies were selected at different organizational levels including project manager, site engineer, safety engineer, quantity surveyor. Table 1 shows the profile of interviewees. With the permission of interviewees, the interviews were recorded. Professionals were asked number of questions including their roles and responsibilities about existing process of safety management at workplace and the difficulties of execution of the roles.

Table 1. Profile of interviewees

\begin{tabular}{|c|l|l|l|c|}
\hline No. & \multicolumn{1}{|c|}{ Project type } & Industry discipline & \multicolumn{1}{|c|}{ Position } & $\begin{array}{c}\text { Year of } \\
\text { experience }\end{array}$ \\
\hline 1 & 23 floor multi-story residential building & Main contractor & Project Manager & 23 \\
\hline 2 & 23 floor multi-story residential building & Owner & Safety Engineer & 6 \\
\hline 3 & 16 floor multi-story building & Main contractor & Quantity Surveyor & 5 \\
\hline 4 & 16 floor multi-story building & Main contractor & Junior Safety Engineer & 6 \\
\hline 5 & 16 floor multi-story building & Owner & Safety Officer & 13 \\
\hline 6 & High rise commercial building & Main contractor & Site Manager & 16 \\
\hline 7 & High rise commercial building & Owner & Safety Engineer & 8 \\
\hline 8 & Smart city underground water system project & Main contractor & Health and Safety Specialist & 11 \\
\hline 9 & Smart city underground water system project & Main contractor & Safety Junior & 5 \\
\hline
\end{tabular}

\section{Current safety practices at Indian construction workplaces}

Through interview, it was found that safety management plans at construction sites were not executed systematically by most of the projects. The project manager was responsible for managing safety at workplace. Due to work pressure, project managers usually focused on the project production. Safety officers and safety engineers were appointed separately to monitor safety and provide training to workers at workplace. Workers were given safety instructions during their supervision. For newly joined workers, induction training was given by safety which professionals specially depends on workers onsite job/task. Tool box talk was conducted every week by safety professionals which were a brief talk on safety concerns. During tool box talk workers were given safety instructions particularly on their job risks and safety. Common safety instructions were also given to workers through mass toolbox talk. Safe operating procedures (SOPs) of all risky activities such as a procedure of shuttering were prepared by safety officers. The procedures specified safety necessities, guidelines and tools. They were linked and complied with company safety guidelines, safety rules, project designs and specifications. The workers were supposed to follow this procedure while working. It was the duty of safety officers to inspect the condition of the workplace in-order to ensure that the safety measures are followed.

\section{Causes of accidents}

Workplace unsafe condition is one of the major reasons for causes of accidents (Zhou et al., 2015). Through interview, a number of major causes were identified at worker level which includes (1) lack of awareness and attitude (2) lack of safety knowledge (3) lack of equipment's and tools (4) violation of code of practice and (5) lack of hazard information.

According to interviewees, the major contributing factors to safety are workers knowledge and attitude. Indian construction industry consists of a large number of unskilled labours. As Interviewee (2) (3) (4) (9) pointed out:

"There is a lack of commitment when safety measures are concerned by the management consequently leading to the careless attitude to the workers. More often, labours enter into work zone without asking for job risks and protection devices from their representatives."

At supervisor level, the major contributing factor for safety is lack of supervision. As Interviewee (6) pointed out: 
"I used to tell that supervision is important. Some supervisors just visited half of the site and came back to their place and some supervisors don't even go to monitor the workers activities. They just told that their workers were instructed to take personal protective equipment's (PPEs) to protect them."

As Interviewee (8) stated that:

"Everyone knows that the supervision is important. Young workers don't have fear and many of them don't even aware of hazards associated with their tasks. Supervisors provide PPEs to workers with incomplete safety knowledge and ask them to protect themselves. Young workers just enter into the site and follow their senior's way of task performing. If workers came to know that someone is watching them then they won't go for any shortcuts to complete their task" (Young, 1996).

The most important revelation by the professionals is that poor safety planning followed by communication are the major factors responsible for risks at organizational level. As per their statement, the professionals were asked about the traditional methods used in construction workplace for safety planning and hazards identification.

As Interviewee (1) (7) replied that:

"Indian regulations are not good enough to identify hazards at construction site. So in that case manual observations, 2D drawings, past experiences and building standards are used for safety planning and hazard identification. Majority of the hazard identification at construction workplace was carried out during construction phase of the projects."

Regarding effectiveness of these methods, (1) (7) stated that:

"It is not sufficient and effective to identify hazards. The fact here is that traditional methods only represent the construction components. They fail to portray the wholistic picture of the site which makes it difficult to monitor the site both individually and constitutively. This results in poor safety planning."

In addition, Interviewee 5 indicated that the use of equipment's and tools are not clearly defined on the site.

\section{Discussion}

Compared to other countries, Indian construction industry is still in the beginning stages of safety law execution. Even though, India has set regulations for construction safety namely The Building and other Construction Workers Safety and Welfare Act of 1996, Factories Act 1948 and The Indian Explosives Act, only some of them are put into practice. National Building Code of India is the set of regulation followed nationwide for regulating activities in building construction. But still, priority for safety is in the bottom level for builders and contractors. Workers are trained by the safety professionals in the construction site. In addition, workers are also being trained how to handle new equipment safely in Indian construction site. Some large scale companies in India started to train their workers through consultancy services. Moreover, to improve safety at site, companies in India has also started to follow other countries regulations and their innovative technologies. India is a country where cost of unskilled and semi-skilled labours are cheap, being unaware of their rights. Thus builders and contractors find it profitable to use such manpower. Many companies do not follow code provisions during the execution of safety regulations. Hence, in these situations, it is significant to bring together IT developments or virtual situation to establish construction process, identify hazards for better safety planning (Bansal, 2011).

According to the previous researches, the involvement of a designer in this concern is the most effective method as they can be aware of the potential hazards at sites and can help in the mitigation of such hazards. Design solutions at a design phase could be given higher priority; this will be cost effective and helpful in controlling hazards at construction sites (Gambatese, 2008). Behm (2005) stated that the inclusion of designers in safety management at sites is essential because the permanent facilities available at sites can influence the rate of accidents. During the design phase the possibility of hazards can be eliminated. The basic idea for design in the area of construction safety is that designs which have a possibility of unnecessary hazards should not be included, if there remains a possibility the construction workers, contractors, sub-contractors and other personnel's must be aware about it, the factors that have an inherent risk must be informed.

For carrying out a preventative control approach, identification of hazards is necessary. The safety management teams should identify the potential hazards before the delivery of a project and the start of activities at construction sites. Carter and Smith (2006) pointed out that according to the present level of knowledge about the safety management; the level of hazard identification is below expectation. Hadikusumo and Rowlinson (2002) stated that as identification of hazards at construction sites is done with the help of drawings and other traditional methods so the task of identifying the risks, may be a difficult one. This may also be a burden in visualizing the real state of affairs at construction sites. Recently, due to the advancement and improvement of the information technology, investigating and adopting various virtual reality (VR)/virtual environment (VE) systems can be of great aid in safety management. VE engages computer-based settings of virtual machines that are combinations of hardware platforms and virtual machine monitors (Stanney \& Hale, 2014). VR are recognised as not only the user's vision with computer 
interfaces, but also the smell, taste, haptic (touch) and sound, which include often real-time communication (Burdea $\&$ Coiffet, 2003). Through these advanced approaches the drawings, sequence of construction and the methods can be visualized beforehand. This can be also used for the identification of potential hazards, training for safety and evaluation.

The safety planning at site depends upon the type of project so before delivery of a project the kinds of risks involved in the project must be minutely identified. This can be done by appointing a team which identifies the risk and conduct meetings with the trade site manager, safety manager and the construction manager in order to get assured. The discussion in the meeting regarding sketches and plans can help in taking preventive measures against the risks at construction sites. The limitations and the problems involved while considering the suggestions derived from the discussion in the meeting may or may not reflect the real ground situation (Jeon \& Park, 2005). Hadikusumo and Rowlinson (2002) suggested that 3D engineering models should be used to reflect the field environments. A 3D virtual site modelling was proposed by ( $\mathrm{Li}, \mathrm{Ma}$, Shen, \& Kong, 2003) which represent the site situations in real. The workforce, equipment's, stockyard and the temporary facilities can also be visualised in this 3D model. Along with this model a safety plan comprising of 6 days was prepared and the feasibility of applications were examined. With this initiative of (Li et al., 2003) other studies also planned to perform and develop virtual models that link safety information with the working schedule. A simulation model was developed by (Chau, Anson, \& Zhang, 2004) which helped in linking the geometric model with bar chart or CPM which in turn can be productive in predicting the potential problems on site. The exemplification of a 4D BIM was done by (Sulankivi, Kähkönen, Mäkelä, \& Kiviniemi, 2010). It was a rule based system for checking safety which was also linked with railing installation schedule and safety guard to prevent accidents from heights. Case report, heuristic knowledge and geometric schedule simulation model (Hadikusumo \& Rowlinson, 2002) virtual 3D model (Bansal, 2011). can be used as database for implementing the safety measures.

During the entire process of construction, controlling the worker's behaviour and monitoring them is an important task which should be performed by the site safety manager efficiently. Inspection of the safety tools and the facilities provided should also be taken into consideration on regular basis. According to the present state of affairs, the manager recruited for checking the safety at sites checks that the preventive measures that were planned are implemented or not, there is a check on the behaviour of the workers also. After the inspection and monitoring the manager reports information about the prevailing conditions to the trades. The use of sources like photos, videos, checklists were helpful for faster communication with the authorities (Chen \& Kamara, 2011).

In another study, the concept of introducing augmented reality (AR) technology for displaying the hazardous situations at sites has been suggested by (Mizuno, Kato, \& Nishida, 2004). This AR technology can be applied to visualize the information related to electrical lines and the location of pipes, which can be hazardous (Wang $\&$ Dunston, 2007). Lee and Akin (2011) practically implemented this idea and developed an AR application which supports the maintenance and the operational tasks to be carried out. This provides a picture of the tasks to be carried out in advance, through which one can think of the potential risks. The components of design- for- safety tool were discussed by (Hadikusumo \& Rowlinson, 2002). The mechanisms of the tool included the components of the virtual reality construction. These components were coupled with the process of construction that utilized the components of design-for-safety process database. The participants were allowed to roam freely in the virtual reality and apply their cognitive skills to prevent the hazardous situations that occur. Perlman, Sacks, and Barak (2014) introspected whether virtual reality learning can improve the capability of risk identification of construction superintendents and civil engineering students. The results point out that there was a positive effect on the superintendents and students as they were able to identify more number of hazards after the VE learning. However the construction superintendents gained an upper hand in identifying the number of hazards as per the data. This point establishes that there is a direct relation between the real life experience and performance in the virtual reality.

\section{Conclusion and recommendations for the future research}

This paper examined the current safety practices and identified the causes of accidents at Indian construction workplaces. It was found that there are lot of loopholes in present traditional safety practices at Indian construction workplace. Results indicated that accidents were caused by the combination of organizational and individual factors. In specific, organizational level include poor safety planning and communication, while individual factors include (1) lack of awareness and attitude (2) lack of safety knowledge (3) lack of equipment's and tools (4) violation of code of practice and (5) lack of hazard information. Note that these factors are derived from stakeholder's individual perceptions based on their experience and not from any reports.

According to the researchers in literature, the involvement of a safety in design is the most effective method and can help in the mitigation of hazards before it occur during construction process. At a global level, there have been efforts in the promotion of application of design for safety in construction industry. Recently, use of ITs has major positive impacts on construction safety. The advancement of ITs has led to an increase in their application potential but still the use of ITs is not prevalent in the construction industry as compared to other industries. There are various kinds of technologies, that can be integrated together according to their use and outcome required to yield a better technology for safety management at construction sites. 
For safety management planning and its proper execution the use of visualization technology is beneficial. To summarize, the BIM technology can be used in Indian construction sites to envisage the conditions prevailing at the construction sites through virtual 3D and 4D models. Creativity with technology is a correct blend to captivate the interests of the workers at sites. In this regard the game technology can be of great aid in enhancing the cognitive abilities towards the risks involved; this can provide a prior experience to deal with risks. Tracking location of the equipment's, tools and people at site can mitigate the number of accidents at construction sites, the AR technology and GPS activation can be used for this purpose. For implementing such plans in reality, there has to be an interaction between the visualization of conditions prevalent on site and the real time situation. This visualization technology needs to be represented as an integrated whole for producing maximum effect. The presence of a unified system is essential to use these technologies and gain advantages. One needs to find feasible solutions for the ease of implementation. Due to the advancement and improvement of the ITs, it can be deduced that implementing these technologies in projects could improve safety performance at Indian construction worksite.

In India, still safety is considered during construction phases of the projects. Safety regulations for Indian construction projects are not reflecting the actual working condition where there is a chance of accidents. In this situation company's management should themselves implement their own regulatory system during design stage of their projects to ensure better safety performance. The future plan involves looking for the implementation and use of ITs in Indian construction industry. As implementation of ITs has been attested as a healthy safety practice, it should be surveyed that how far Indian construction sector is benefiting from this technology. An investigation regarding the barriers in the implementation of ITs should also be carried out in order to discover a feasible solution.

One of the major limitations is that this study was conducted in sourthern part of India. In future, the research should be carried out in other regions of India so that the comparative assessment is possible. This will help in understanding the Indian construction safety scenario in a better way. Another major limitation is that this study only considers large scale construction sectors. Further research should also carry out with small and medium scale construction sectors. This study does not provide a holistic approach to the problem; other common situations should be identified in future studies. This study did not collect the viewpoint of workers were not involved. The future studies will also focus on the comments of workers regarding the occurrence of accidents at workplace and other issues.

\section{References}

Bansal, V. K. (2011). Application of geographic information systems in construction safety planning. International Journal of Project Management, 29(1), 66-77. https://doi.org/10.1016/j.ijproman.2010.01.007

Bashir, A. M., Suresh, S., Proverbs, D., \& Gameson, R. (2011). A critical, theoretical, review of the impacts of lean construction tools in reducing accidents on construction sites. In C. Egbu, \& E. C. W. Lou (Eds.), Proceedings of the 27th Annual ARCOM Conference, 5-7 September (pp. 249-258). Bristol, UK, Association of Researchers in Construction Management.

Behm, M. (2005). Linking construction fatalities to the design for construction safety concept. Safety Science, 43(8), 589-611. https://doi.org/10.1016/j.ssci.2005.04.002

BLS. (2017). National census of fatal occupational injuries. United States Department of Labour. Retrieved from https://www.bls.gov/news.release/pdf/cfoi.pdf

Burdea, G. C., \& Coiffet, P. (2003). Virtual reality technology (2 ${ }^{\text {nd }}$ ed). New York: John Wiley \& Sons. https://doi.org/10.1162/105474603322955950

Carter, G., \& Smith, S. D. (2006). Safety hazard identification on construction projects. Journal of Construction Engineering and Management, 32(2), 197-205. https://doi.org/10.1061/(ASCE)0733-9364(2006)132:2(197)

Chau, K. W., Anson, M., \& Zhang, J. P. (2004). Four-dimensional visualization of construction scheduling and site utilization. Journal of Construction Engineering and Management, 130(4), 598-606. https://doi.org/10.1061/(ASCE)0733-9364(2004)130:4(598)

Chen, Y., \& Kamara, J. M. (2011). A framework for using mobile computing for information management on construction sites. Automation in Construction, 20(7), 776-788. https://doi.org/10.1016/j.autcon.2011.01.002

Fewings, P. (2013). Construction project management: an integrated approach (2 $2^{\text {nd }}$ ed). New York: Routledge. https://doi.org/10.4324/9780203831199

Gambatese, J. A. (2008). Research issues in prevention through design. Journal of Safety Research, 39, 153-156. https://doi.org/10.1016/j.jsr.2008.02.012

Guo, H. L., Li, H., \& Li, V. (2013). VP-based safety management in large-scale construction projects: a conceptual framework. Automation in Construction, 34, 16-24. https://doi.org/10.1016/j.autcon.2012.10.013

Hadikusumo, B. H. W., \& Rowlinson, S. (2002). Integration of virtually real construction model and design-for-safety-process database. Automation in Construction, 11(5), 501-509. https://doi.org/10.1016/S0926-5805(01)00061-9

Hämäläinen, P. (2010). Global estimates of occupational accidents and fatal work-related diseases (Publication vol. 917). Tampere: Tampere University of Technology.

HSE. (2006). Analysis of the significant causes of fatal and major injuries in construction in Scotland (Research Report No. 443). Glasgow. Retrieved from http://www.hse.gov.uk/research/rrpdf/rr443.pdf

HSE. (2018). Workplace fatal injuries in Great Britain. Annual Statistics Great Britain. Retrieved from http://www.hse.gov.uk/statistics/pdf/fatalinjuries.pdf 
Huang, X., \& Hinze, J. (2003). Analysis of construction worker fall accidents. Journal of Construction Engineering and Management, 129(3), 262-271. https://doi.org/10.1061/(ASCE)0733-9364(2003)129:3(262)

Jeon, Y. S., \& Park, C. S. (2005). A study on the framework of the continuous improvement model of construction process using construction failure information. Korean Journal of Construction Engineering and Management, 6(1), 195-204.

JIOSH. (2017). Ministry of Health, Labour and Welfare's Industrial Accident Occurrence. Status Japan. Retrieved from https://www.jisha.or.jp/english/statistics/pdf/outline_of_2017.pdf

Lee, S., \& Akin, Ö. (2011). Augmented reality-based computational fieldwork support for equipment operations and maintenance. Automation in Construction, 20(4), 338-352. https://doi.org/10.1016/j.autcon.2010.11.004

Li, H., Ma, Z., Shen, Q., \& Kong, S. (2003). Virtual experiment of innovative construction operations. Automation in Constuction, 12(5), 561-575. https://doi.org/10.1016/S0926-5805(03)00019-0

Mizuno, Y., Kato, H., \& Nishida, S. (2004). Outdoor augmented reality for direct display of hazard information. In SICE 2004 Annual Conference (vol. 1, pp. 831-836), Sapporo.

OSHB. (2017). Occupational safety and health statistics. Labour department. The Government of the Hong Kong Special Region. Retrieved from https://www.labour.gov.hk/eng/osh/pdf/OSH_Statistics_2017_EN.pdf

Patel, D. A., \& Jha, K. N. (2016). An estimate of fatal accidents in Indian construction. In P. W. Chan, \& C. J. Neilson (Eds.), Proceedings of the $32^{\text {nd }}$ Annual ARCOM Conference (vol. 1, pp. 577-586), 5-7 September, Manchester, UK, Association of Researchers in Construction Management.

Perlman, A., Sacks, R., \& Barak, R. (2014). Hazard recognition and risk perception in construction. Safety Science, 64, $22-31$. https://doi.org/10.1016/j.ssci.2013.11.019

Pingle, S. (2012). Occupational safety and health in India: now and the future. Industrial Health, 50(3), $167-171$. https://doi.org/10.2486/indhealth.MS1366

Stanney, K. M., \& Hale, K. S. (2014). Handbook of virtual environments: design, implementation, and applications. CRC Press.

Sulankivi, K., Kähkönen, K., Mäkelä, T., \& Kiviniemi, M. (2010). 4D-BIM for construction safety planning. In Proceedings of W099-Special Track $18^{\text {th }}$ CIB World Building Congress (pp. 117-128).

Vigneshkumar, C., Salve, U. R., \& Saravana, M. K. (2018). Differences of Occupational Health and Safety Management System (OHSMS) consciousness among Indian construction industry. In Proceedings of Urbanization Challenges in Emerging Economies: Energy and Water Infrastructure; Transportation Infrastructure; and Planning and Financing, ASCE India Conference 2017. https://doi.org/10.1061/9780784482025.044

Wang, X., \& Dunston, P. S. (2007). Design, strategies, and issues towards an augmented reality-based construction training platform. Journal of Information Technology in Construction (ITcon), 12(25), 363-380.

Young, S. (1996). Construction safety: a vision for the future. Journal of Management in Engineering, 12(4), 33-36. https://doi.org/10.1061/(ASCE)0742-597X(1996)12:4(33)

Zhou, Z., Goh, Y. M., \& Li, Q. (2015). Overview and analysis of safety management studies in the construction industry. Safety Science, 72, 337-350. https://doi.org/10.1016/j.ssci.2014.10.006 